\title{
The importance of soil erosion for surface waters in the case of Rotbach Creek
}

\author{
E. Christoffels \\ Erftverband, Bergheim, Germany
}

\begin{abstract}
Entry of solids into surface waters originating from soil erosion is accounted for as an event-specific input which reaches rivers via diffuse pathways. The hydromorphological condition and substance content of surface waters can be significantly impacted by these entries. The sand-gap system on the river bed, the habitat for the greatest part of aquatic fauna, can become clogged by solid entries rich in fine material. Compared to river stretches naturally rich in fine solids, those dominated by gravel substrate are more adversely influenced by entries from soil erosion. Nutrients and pollutants enter surface waters in association with solids. Measurements conducted in the Rotbach catchment in the state of North Rhine-Westphalia, Germany, confirm the importance of entries from soil erosion. The measurement results for Rotbach Creek provide an example of enormous masses of solids entering a surface water through soil erosion. Inputs of phosphorus, cadmium and herbicides are considerable. The good status required by the European Water Framework Directive cannot be achieved without appropriate measures to address farming practice.

Keywords: monitoring, nutrients, pesticides, rainfall erosivity, rainfall intensity, soil erosion.
\end{abstract}

\section{Introduction}

A complete set of measures to improve the ecological status of a watercourse, while taking into account nutrient and pollutant loads, necessarily addresses hydromorphological deficits as well. These are commonly linked with hydraulically engineered works such as technically developed longitudinal and transverse profiles, constructed bed or bank protection, migration barriers and systems that regulate water flow (weirs, barrages and turbines). However, 
there is another key factor associated with hydromorphological deficits which merits close attention: soil erosion. Particles washed out of topsoil in the vicinity of watercourses are deposited on the river bed; rich in fine material, these solids can significantly modify the structure of the substrate. As carriers of nutrients such as phosphorus and a wide variety of contaminants, they can also adversely affect ecological status.

\section{Spatio-temporal scale of substance input}

Watercourses both collect material from and return material to the surrounding landscape. Transfer of substances from adjacent landscape, from urban areas and from the atmosphere into a watercourse is defined as substance input. The transport medium is either water or air. Transport into the watercourse may take place at a geographically defined point or without a clear spatial delimitation; a distinction is hereby made between point and diffuse inputs (table 1). An example of a diffuse entry is when substances that are washed out from the land surface by rainfall reach the watercourse via flow pathways which are not clearly determined (e.g. spatially branched). Entry of solids originating from soil erosion is thus accounted for as diffuse input (table 1).

Substance input pathways can also be distinguished in terms of temporal type of discharge process: event-specific; episodic; and continuous flow. All runoff components can be considered as one of these types (table 2). The entries from soil erosion are in direct temporal association with erosive rainfall events; the time span of entry events is associated with duration of the triggering precipitation event. Thus, entries from soil erosion are counted with the eventspecific entries which reach rivers via diffuse pathways.

Precipitation patterns are one of the controlling factors in soil erosion. Volume and intensity determine whether precipitation has the potential to be erosive. With summer heat the precipitation brought by storms increases significantly in both volume and intensity compared with precipitation at other times of year (figure 1). Since raindrop diameter and fall velocity both rise with increasing intensity (Symader [1]), the potential to trigger soil erosion increases disproportionally to the precipitation amount. A significantly higher risk of rainfall erosivity is thus to be expected in summer compared to the rest of the year.

Table 1: Substance input into rivers according to spatial criteria.

\begin{tabular}{|c|c|}
\hline \multicolumn{2}{|c|}{ Substance input } \\
\hline $\begin{array}{l}\text { Point source } \\
\end{array}$ & Diffuse source \\
\hline Wastewater treatment plant effluent & Surface runoff \\
\hline Direct discharge & Erosion \\
\hline from trade/industry & Drainage \\
\hline Combined sewer overflow & Groundwater \\
\hline Stormwater discharge & Atmospheric direct deposition \\
\hline
\end{tabular}


Table 2: Substance inputs into rivers according to temporal criteria.

\begin{tabular}{|l|l|}
\hline \multicolumn{1}{|c|}{ Flow component } & Discharge into surface waters \\
\hline Wastewater treatment plant effluent & Continuous \\
\hline Combined sewer overflow & \multirow{2}{*}{ Event specific } \\
\hline Stormwater discharge & Continuous \\
\hline Groundwater runoff & Episodic \\
\hline Subsurface runoff (interflow) & Event specific \\
\hline Surface water runoff &
\end{tabular}

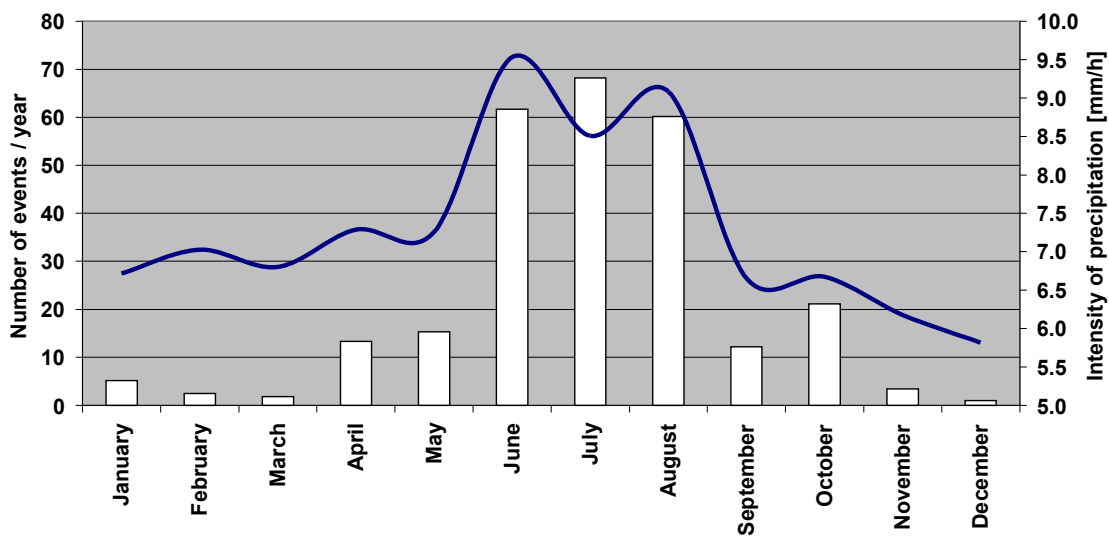

Average number of events per year with $>5.4 \mathrm{~mm} / \mathrm{h}$ - Average intensity of precipitation

Figure 1: Seasonal distribution of the frequency of storm events $(>5.4 \mathrm{~mm} / \mathrm{h}$; according to critical rainfall intensity $\mathrm{rcrit}=15 \mathrm{~L} / \mathrm{s} / \mathrm{ha}$ (Imhoff and Imhoff [2]) and associated average rainfall intensity in the Erft river basin (Christoffels [3]).

Ground coverage provided by plants also plays an important role in soil erosion. For example, coverage provided by wheat differs substantially from that provided by maize. Figure 2 shows the seasonal distribution of rainfall erosivity and the degree of ground coverage provided by wheat and maize over the entire year. The time window of elevated erosion risk is clearly much wider with maize crops than with crops of wheat. With maize, vegetative coverage of $60 \%$ is not achieved before the middle of August, when the most erosive rainfall of the year has already occurred. According to Auerswald [4], it is assumed that under the same conditions four times more soil is removed through erosion in maize monoculture than under cereal crop rotation. 
[\%]

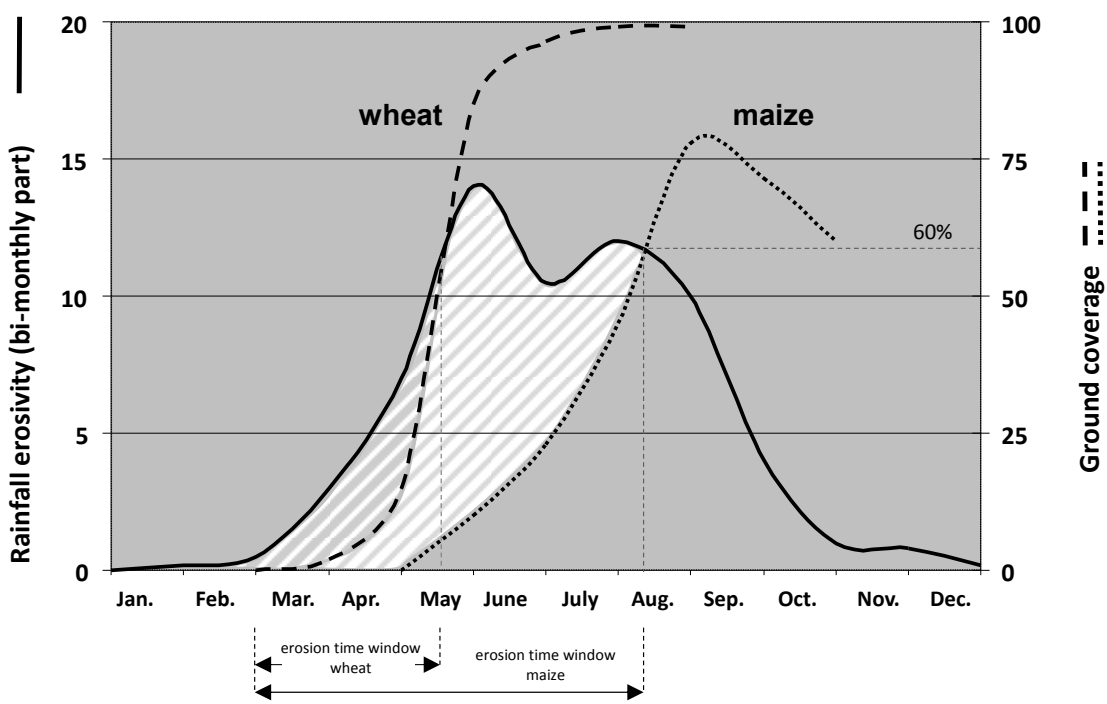

Figure 2: Rainfall erosivity (annual distribution of bi-monthly values) and crop-specific coverage of soil over the year according to Auerswald [4], assumption for time span of erosion: $0 \%$ to $60 \%$ ground cover.

\section{Importance of inputs from erosion}

The importance of erosion as a cause of substance input into surface waters is highlighted by the findings of German nationwide surveys on substance input into surface waters. This is especially true for the nutrient phosphorus, for which soil erosion accounts for $22 \%$ of the total inputs (table 3 ). This also holds for heavy metals, in particular chromium and lead, for which a high proportion of inputs stems from geogenic sources (figure 3). It should be noted that the emission inventories upon which these statements are based provide only rough estimates. Accordingly, the proportions which are given in figure 3 and table 3 serve as orientation values. 
Table 3: Nitrogen and phosphorus discharges into surface waters, Germany (Umweltbundesamt [5]).

\begin{tabular}{|c|c|c|}
\hline & Nitrogen [t/a] & Phosphorus [t/a] \\
\hline Non-point inputs & $590000(72 \%)$ & $24500(66 \%)$ \\
\hline Agriculture & $530000(67 \%)$ & $20500(55 \%)$ \\
\hline - Surface runoff & - $15000(2 \%)$ & • $3500(9 \%)$ \\
\hline - Field drainage & - $120000(15 \%)$ & - $3500(9 \%)$ \\
\hline - Erosion & - $15000(2 \%)$ & - $8000(22 \%)$ \\
\hline - Groundwater & - $395000(48 \%)$ & - $5500(15 \%)$ \\
\hline Atmospheric deposition & $10000(1 \%)$ & $<0.5$ \\
\hline Built-up areas & $35000(4 \%)$ & $4000(11 \%)$ \\
\hline Point inputs & $230000(28 \%)$ & $12500(34 \%)$ \\
\hline Industry & $25000 \quad(3 \%)$ & $1000(3 \%)$ \\
\hline $\begin{array}{l}\text { Municipal wastewater } \\
\text { treatment plants }\end{array}$ & $205000(25 \%)$ & $11500(31 \%)$ \\
\hline
\end{tabular}

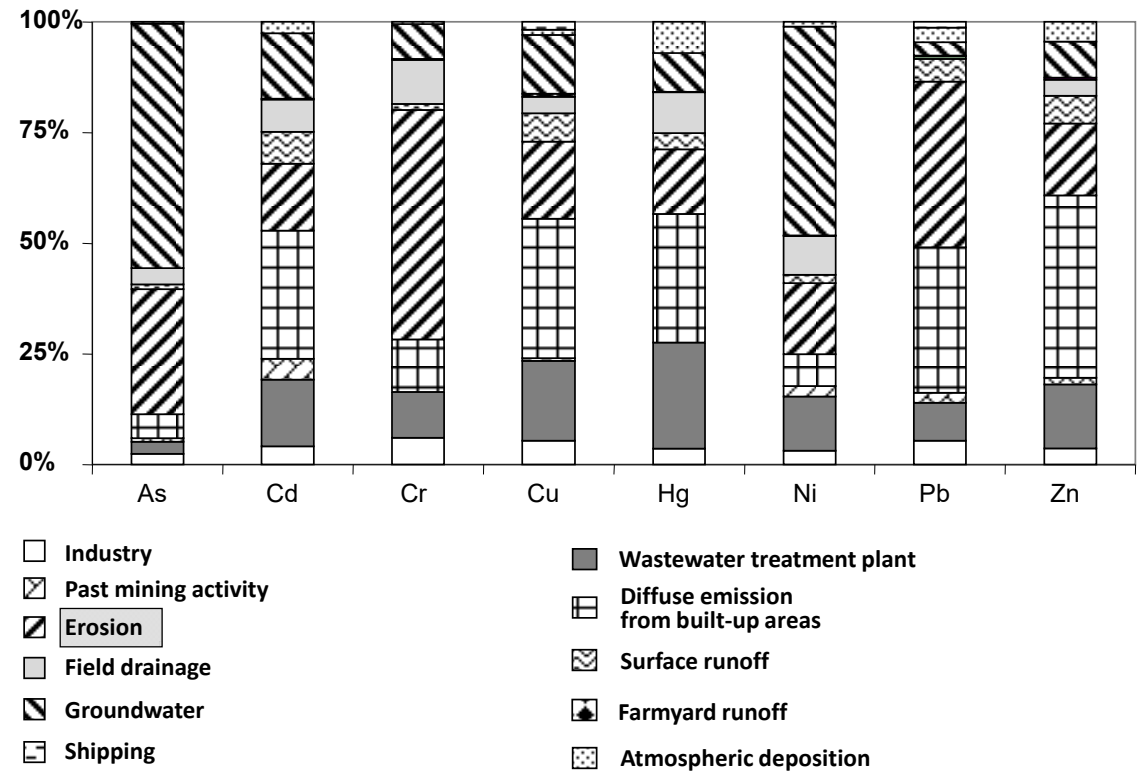

Figure 3: Heavy metal emissions in river basins, Germany (Umweltbundesamt [6]). 


\section{Pressure on surface waters stemming from erosion}

The event-specific, diffuse input from soil erosion exerts two distinct types of pressure on surface waters. One pressure is the substance load, while the other is hydromorphological.

Substance load

- Nutrients

- Pesticides; and

- Other compounds.

Hydromorphological pressure

- Changes in substrate properties (sediment and bedload)

- Influence on aquatic habitat (sand-gap system).

Eroded soil delivers a substance load made up of residues of chemicals used in agriculture, pharmaceuticals and heavy metals mobilised by farming activity. In agriculture fertilising compounds are applied to increase crop yields. A portion of nutrients (e.g. phosphorus) is adsorbed onto soil solids and can enter surface waters through soil erosion. Likewise, crop protection chemicals (e.g. pesticides) as well as heavy metals (soil-borne/impurities in fertiliser) can be mobilised and washed into watercourses. In addition, veterinary pharmaceutical residues reach the soil in manure applications, while residues from pharmaceuticals used to treat humans can be present in soil which has received applications of sewage sludge. Again, entry into surface waters takes place when soil sediments erode.

The entry of solids through soil erosion also leads to modification of hydromorphological conditions in the receiving water. For small and medium sized watercourses, which are far more numerous than large ones, the riverbed is known to be the preferred habitat for aquatic life.

Solids rich in fine materials are washed into watercourses and subsequently dispersed more or less widely depending on particle size. They tend to ultimately settle on the bed in parts of the watercourse where water flows relatively slowly. Such areas of calm water provide valuable spawning habitat as well as shelter for juvenile fish. A threat to aquatic life arises when deposition of transported solids into the pores of the riverbed results in clogging of the sand-gap structure, which can lead to significant depletion of benthic invertebrates and fry. In particular, for coenosis adapted to gravel substrate, the sometimes enormous entries of solids disturb the established ecosystem. Compared to river stretches naturally rich in fine solids, those dominated by gravel substrate are more adversely influenced by entries from soil erosion.

The European Water Framework Directive [7] contains a provision for classification of aquatic biological status based on biological quality elements comprising macrophytes, phytobenthos/-plankton, invertebrates and fish. 
Table 4: Assessment of relevance of entries from soil erosion for the biological quality elements of the European Water Framework Directive $(++=$ very relevant, $+=$ relevant, $-=$ less relevant, o = may be relevant) (DWA-M 910 [8]).

\begin{tabular}{|c|c|c|c|c|c|}
\hline & $\begin{array}{l}\text { Water body } \\
\text { structure }\end{array}$ & \multicolumn{4}{|c|}{ Water quality } \\
\hline Biological quality elements & 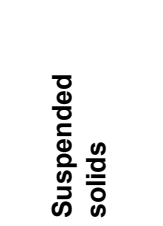 & 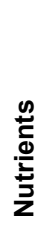 & $\begin{array}{l}\frac{0}{\pi} \\
\frac{\pi}{0} \\
\sum\end{array}$ & $\begin{array}{l}0 \\
\stackrel{0}{0} \\
\frac{0}{0} \\
\stackrel{0}{0} \\
0 \\
0 \\
0\end{array}$ & 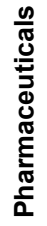 \\
\hline Macrophytes & ++ & + & 0 & o & 0 \\
\hline Phytobenthos /-plankton & - & + & o & o & o \\
\hline Macrozoobenthos & ++ & 0 & + & ++ & ++ \\
\hline Fish & ++ & - & + & ++ & ++ \\
\hline
\end{tabular}

Assessment of pressures on watercourses stemming from soil erosion can be made using these elements, which are influenced by entries from soil erosion to varying degrees.

In table 4, the relevance of entries from soil erosion for biological quality elements is shown according to studies in the catchment of the river Erft. It is apparent that solids are highly relevant due to clogging or superposition of coarse sediments with fine sediments for macrophytes, macroinvertebrates and fish fauna. Impounded river sections are particularly troublesome because solids settle easily due to low flow velocity. Nutrients are primarily important for macrophytes, phytoplankton and phytobenthos, while entries of metals from applied fertilizer or existing soil are relevant for benthic invertebrates and fish fauna. Pesticides and pharmaceuticals from sludge and from agricultural manure applications are of great importance for benthic invertebrates and fish fauna.

\section{Methods of monitoring to detect entries}

So far, there is little data detailing the substances discharged into watercourses by soil erosion and at what magnitude. There are crucial reasons for this lack. Since entries stemming from soil erosion are diffuse, the discharged loads can be reliably measured only in the surface waters. However, due to the relatively limited number of parameters measured with in-situ sensors, data gathered with them is unsuitable, as the amount of information they deliver is insufficient. It is thus essential to obtain representative water samples for which all relevant parameters can then be analysed in the laboratory. For this purpose, the sampling location must be placed as close as possible downstream to the entry of eroded material. Otherwise, deficiencies in findings are to be expected because of downstream deposition of discharged substances as sediments.

Since erosion events are dependent on the behavior of precipitation events, they are highly unpredictable. Moreover, erosion events are often of such short 
duration that it is not feasible to measure the resulting substance input with conventional monitoring techniques such as grab sampling. In addition, since the substance load entering the watercourse varies throughout the duration of the erosion event, the sampling period must span the entire event to enable formulation of valid statements concerning load. Under these conditions, automated sampling of the water column, not grab sampling, must be performed to obtain a complete data profile on entries due to soil erosion in stretches where the adjacent land is subject to substantial erosion. Note that pending transport to the laboratory, it is vital to ensure that the samples are kept on site in appropriate conditions (cool, dark, closed). In summary, within the framework of a suitable monitoring strategy, the gathering of data on surface waters influenced by soil erosion should take into account the following factors:

- $\quad$ Largely unpredictable occurrence of events

- Narrow time window of events

- Instationary behavior of discharge

- Dynamic substance concentration gradients.

For a system which performs automatic sampling in surface waters below erosion-prone areas, the following requirements apply:

- Activation of sampling system occurs at significantly increasing water flow

- Sampling/filling of bottles designed to respond to dynamic progression of substance concentrations

- Sampling adapted to event duration

- Volume of each sample sufficient for laboratory analysis

- $\quad$ Detailed message sent automatically to operating personnel.

\section{Results from the Rotbach catchment and discussion}

Eroded material enters the watercourses of the Erft catchment in the upper (southern) reaches, primarily in the sub-catchment of the $30-\mathrm{km}$ long Rotbach Creek. This $230 \mathrm{~km}^{2}$ sub-catchment consists primarily of farmland planted to row crops. The upper part is classified as low mountain range, with the narrow creek valley deeply cut into the landscape known as the Mechernicher Voreifel. At the village called Schwerfen the steep slopes of the valley recede and from here the Rotbach flows into the Lower Rhine Basin (Erftverband [9]). Through heavy rainfall in the upper sub-catchment, significant soil erosion is triggered on the agricultural land, not least because of the considerable steepness of the slope (figure 4). During stormwater events suspended solids in the Rotbach rise considerably with the entries from soil erosion. An additional factor contributing to the high content of solids in the watercourse is remobilisation of sediment due to increased rate of flow. The typical red-brown color of the water, hence the name Rotbach (in English Red Creek), is the consequence of the high iron oxide and iron hydroxide content of the soil. 


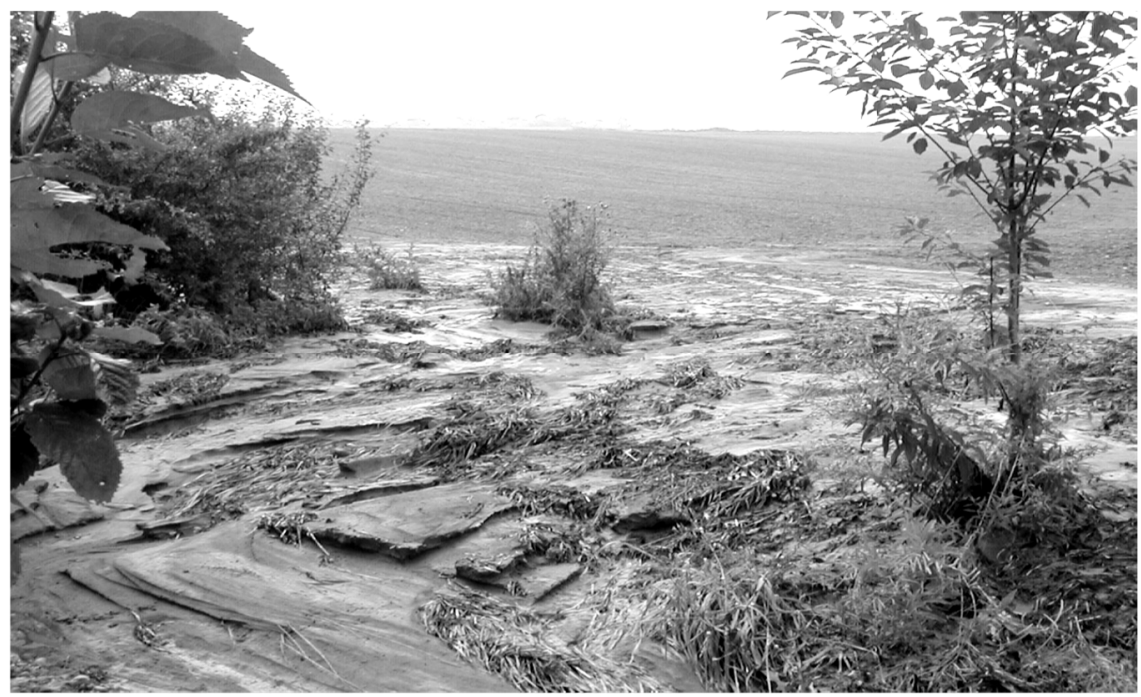

Figure 4: Field along the upper Rotbach on 28 August 2002 after heavy rainfall.

The village of Schwerfen represents the outlet of the erosion delivery zone for the Rotbach sub-catchment. At this location, a gauge to measure the water level is in continuous operation. An automated sampling system has been placed in the housing of this gauge. With this configuration the prevailing water level can be used as a trigger to activate the sampler. The sampling system is automatically cleaned with compressed air once per hour to remove any deposits. When the water level rises significantly, the sampler is activated such that a maximum of 24 sampling bottles receive $1 / 2$ litre within preset time intervals for each bottle. The duration of filling follows an upward progression from 2 minutes for the first bottle and increasing to 80 minutes for the 24th bottle. This procedure permits the securing of samples over the entire duration of almost all erosion events. The samples thus obtained are of high temporal resolution considering the highly dynamic concentration gradients. The set of parameters measured includes among others suspended solids, nutrients, heavy metals, pesticides and pharmaceuticals.

Figure 5 shows the effects of soil erosion in the Rotbach Creek during and after a typical heavy rainfall event which occurred on 20-21 May 2012. The dry weather flow of the Rotbach before the event amounted to $0.1 \mathrm{~m}^{3} / \mathrm{s}$. With stormwater in the late afternoon $(16: 38 \mathrm{~h}$ to $18: 13 \mathrm{~h}$, precipitation $12.5 \mathrm{~mm})$ the runoff of the Rotbach increased to $5.9 \mathrm{~m}^{3} / \mathrm{s}$ by $18: 35 \mathrm{~h}$ (table 5 ). The solid load from 18:00 h on 20 May to 9:00 h on 21 May (15-hour period) amounted to 1047 tons dry weight. During times of average flow the 24-hour solid load amounts to only $70 \mathrm{~kg}$ dry weight. 


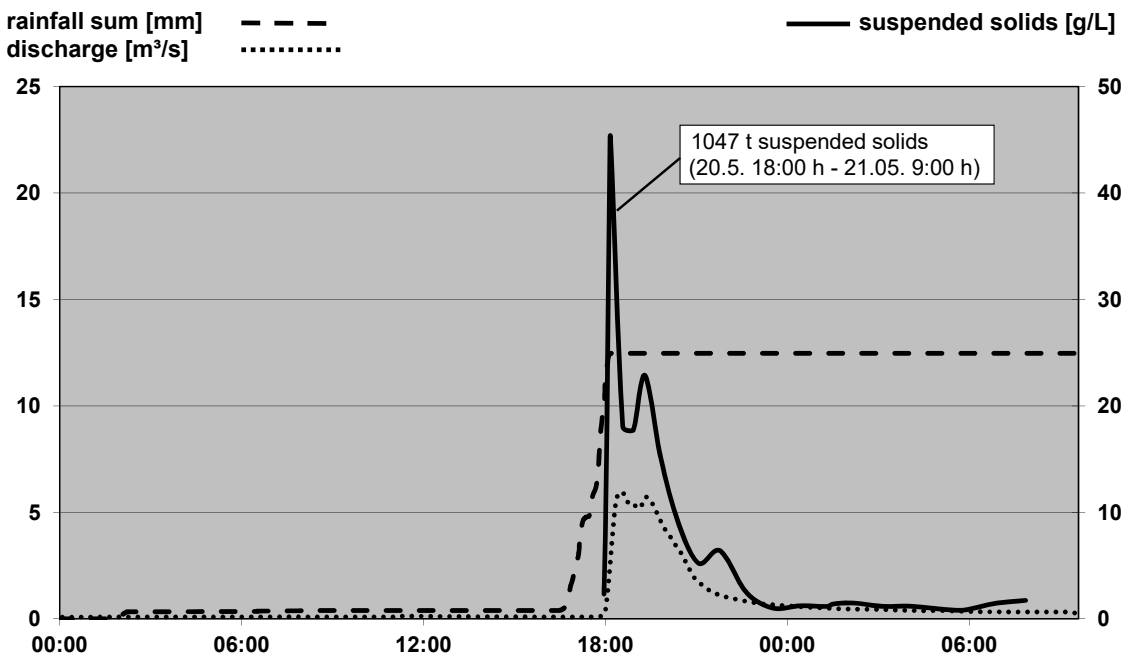

Figure 5: Precipitation sum (Vlatten monitoring station), water runoff and content of suspended solids in the Rotbach Creek at Schwerfen during the erosion event of 20/21 May 2012.

Table 5: Measuring data of the erosion event of 20 May 2012 at Schwerfen water gauge and Vlatten rain gauge.

\begin{tabular}{|l|l|}
\hline \multicolumn{1}{|c|}{ Precipitation/runoff } & \multicolumn{1}{|c|}{ Measuring data } \\
\hline $\begin{array}{l}\text { Total precipitation } \\
\text { 20.05.2015 } 16: 38 \mathrm{~h}-18: 13 \mathrm{~h}\end{array}$ & $12.5 \mathrm{~mm}$ \\
\hline $\begin{array}{l}\text { Average rainfall intensity } \\
\text { 20.05.2015 16:38 h-18:13 h }\end{array}$ & $9 \mathrm{~mm} / \mathrm{h}$ \\
\hline Rainfall-induced runoff volume & $64000 \mathrm{~m}^{3}$ \\
\hline Duration of significantly increased runoff & $15 \mathrm{~h}$ \\
\hline Maximum runoff & $5.9 \mathrm{~m}^{3} / \mathrm{s}$ \\
\hline Runoff peak & $18: 35 \mathrm{~h}$ \\
\hline Maximum increase of runoff $(18: 10 \mathrm{~h}-18: 15 \mathrm{~h})$ & $292 \mathrm{~L} / \mathrm{min}$ \\
\hline Dry weather flow & $100 \mathrm{~L} / \mathrm{s}$ \\
\hline
\end{tabular}

The phosphorus load which arose from the erosion event amounted to $673 \mathrm{~kg}$ over the 15 hours. This corresponds to the load over a period of 339 days under dry weather conditions (figure 6). For cadmium, which is soil-borne and possibly originates from mineral fertilizers, a significantly increased load was also detected. Under provisions of the German Surface Water Ordinance OGewV [10], cadmium is classified as a priority substance in EQS concentrations (EQS $=$ ecological quality standard) which range from $\leq 0.08$ to $0.25 \mu \mathrm{g} / \mathrm{L}$ as annual average concentration (AA-EQS) and as maximum allowable concentration (MAC-EQS) from $\leq 0.45$ to $1.5 \mu \mathrm{g} / \mathrm{L}$ depending on the category of water hardness. 


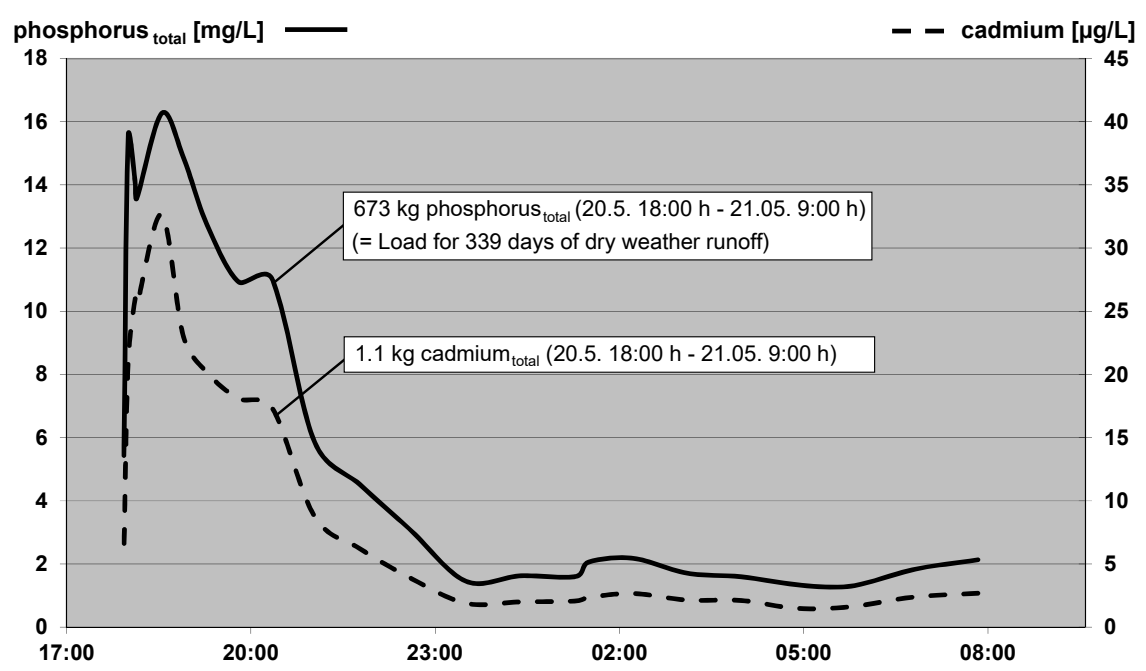

Figure 6: Phosphorus and cadmium concentrations in the Rotbach Creek at Schwerfen during the erosion event of 20/21 May 2012.

During the erosion event various herbicides also entered the Rotbach, of which the most notable were isoproturon (winter wheat); metamitron and chloridazon (beets); and terbuthylazine (maize). According to the German Surface Water Ordinance isoproturon is classified as a priority substance with $\mathrm{AA}-\mathrm{EQS}=0.3 \mu \mathrm{g} / \mathrm{L}$ and MAC-EQS $=1 \mu \mathrm{g} / \mathrm{L}$. Moreover, chloridazon with EQS $=0.1 \mu \mathrm{g} / \mathrm{L}$ and terbuthylazine with $\mathrm{EQS}=0.5 \mu \mathrm{g} / \mathrm{L}$ are designated as so-called river basin specific pollutants. Metamitron is not listed in the German Surface Water Ordinance. For isoproturon a maximum concentration below the MACEQS was measured at $0.85 \mu \mathrm{g} / \mathrm{L}$. With a maximum concentration of $10.3 \mu \mathrm{g} / \mathrm{L}$ for chloridazon, the EQS was exceeded substantially. For terbuthylazin the maximum measured concentration of $7.1 \mu \mathrm{g} / \mathrm{L}$ is also above the EQS. The highest herbicide concentration was measured at $50 \mu \mathrm{g} / \mathrm{L}$ for metamitron. In figure 7 , concentrations and loads of metamitron and chloridazon are shown for the aforementioned erosion event of May 2012.

The measurement results for the Rotbach Creek provide an example of enormous masses of solids entering a surface water through soil erosion. Inputs of phosphorus, cadmium and herbicides are considerable. The input of the heavy metal cadmium, while of local significance in the Rotbach sub-catchment, is relatively insignificant in the main watercourse because of persistently high heavy metal loads originating from a former ore mine draining into an Erft tributary upstream of the Rotbach.

Concentrations of pharmaceutical residues associated with erosion have been unremarkable in the Rotbach in measurements taken up to present. However, the program of monitoring for pharmaceuticals has now been significantly expanded. It remains to be seen whether pharmaceuticals will be detected under this program. 


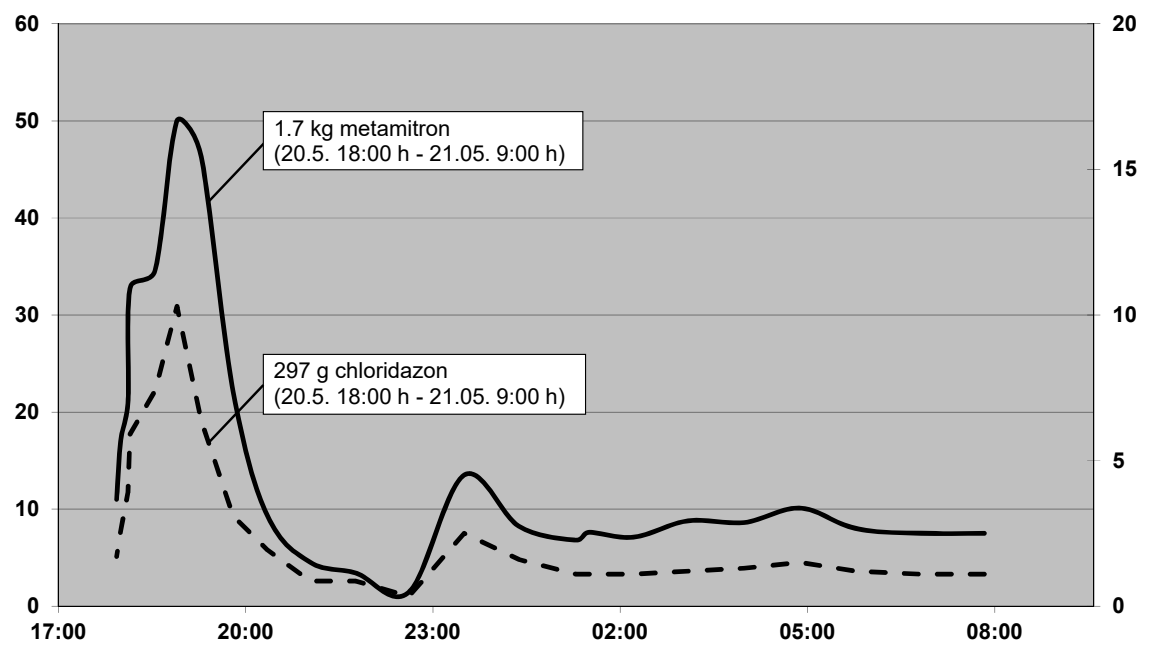

Figure 7: Metamitron and chloridazon concentrations in the Rotbach Creek during the erosion event of 20/21 May 2012.

\section{Conclusion}

The entry of solids and associated nutrients and pollutants from eroded soil into surface waters is highly significant from the point of view of water management. The sand-gap system on the river bed, habitat for the greatest part of aquatic fauna, can become clogged by solid entries rich in fine material. Solids originating from eroded soil accumulate in flow abated stretches, especially in storage influenced riverine sections. Valuable habitat and spawning grounds silt up through deposition of solids in areas of calm water. Nutrients and pollutants enter surface waters in association with solids. Studies conducted nationwide in Germany prove the relevance of these entries. On a local level, measurements conducted in the Rotbach catchment in the state of North Rhine-Westphalia likewise confirm the importance of entries from soil erosion. It should be noted that with soil erosion organic solids enter the water and decay there, which contributes to a reduction in oxygen content. Another example of the impact of soil erosion on water management practice concerns abrasive effects of mineral solids stemming from eroded soil. Such particles can complicate operation of engineered structures and lead to premature deterioration of their constituent parts or materials, e.g. cylinders in weirs.

The entries into surface waters from eroded soil can significantly impact the hydromorphological condition and the substance content of surface waters. In erosion-prone areas, the good status required by the European Water Framework Directive cannot be achieved without appropriate measures to address farming practice. Agriculture and water management are thus called upon to jointly develop workable, effective and cost-efficient measures. Priority will be given to 
measures to prevent soil erosion in farmed areas. In the DWA leaflet "Consideration of Soil Erosion by Water in Planning of Measures According to the EU Water Framework Directive", published in 2012, plentiful advice is offered on how to undertake cost-efficient measures to reduce soil erosion.

\section{Acknowledgement}

The studies presented here were carried out with funds provided by the European Union Life+ -project, "Application of Integrative Modelling and Monitoring Approaches for River Basin Management Evaluation”. The author is grateful for this financial support.

\section{References}

[1] Symader W. 2004 Was passiert, wenn der Regen fällt? Eine Einführung in die Hydrologie (What Happens When the Rain Falls? An Introduction to Hydrology), Verlag Eugen Ulmer, UTB 2496, ISBN 3-8252-2496-1, Stuttgart.

[2] Imhoff K. and Imhoff K. R. 1999 Taschenbuch der Stadtentwässerung (Pocket Guide to Urban Drainage), 29. Auflage, Verlag Oldenburg, ISBN 3-486-26333-1, München.

[3] Christoffels E. 2008 Monitoring und Modellanwendung - Entwicklung eines Immissionsinventars am Beispiel der Erft (Monitoring and Modelling - Development of an Immission Inventory with the Example of the Erft River), Erftverband, ISBN 978-3-00-024445-2, Bergheim.

[4] Auerswald K. 2001 Bodenerosion durch Wasser - Prozesse der Ablösung und des Transports. In: Richter, G. "Bodenerosion - Analyse und Bilanz eines Umweltproblems" (Soil erosion through water - processes of dissolution and transport, in Richter, G. "Soil erosion - Analysis and Result of an Environmental Problem"), Wissenschaftliche Buchgesellschaft, ISBN 978-3534125746, Darmstadt.

[5] Umweltbundesamt 1999 Nährstoffbilanzierung der Flussgebiete Deutschlands (Inventory of Nutrients in River Basins of Germany), Forschungsbericht 29625515 UBA-FB 99-087, Berlin.

[6] Umweltbundesamt 2002 Schwermetalleinträge in die Oberflächengewässer Deutschlands (Heavy Metal Inputs in Surface Waters of Germany), Forschungsbericht 20022233 UBA-FB 000328, Berlin.

[7] Water Framework Directive 2000 Directive 2000/60/EC of the European Parliament and of the Council of 23 October 2000 (Establishing a Framework for Community Action in the Field of Water Policy).

[8] DWA-M 9102012 Berücksichtigung der Bodenerosion durch Wasser bei der Maßnahmenplanung nach EG-Wasserrahmenrichtlinie (Information Sheet DWA-M 910 Consideration of Soil Erosion through Water in Planning of Measures According to European Water Framework Directive), ISBN 978-3-942964-66-1, Hennef. 
[9] Erftverband 1998 Jahresbericht (Annual Report), Eigenverlag, Bergheim.

[10] OGewV 2011 Oberflächengewässerverordnung: Verordnung zum Schutz der Oberflächengewässer (German Surface Water Ordinance: Regulation on the Protection of Surface Waters), Bundesgesetzblatt I, 1433-1435. 